\title{
sciendo
}

Research Article

C 2019 Isabel Pla-Julián and Jose-Luis Díez This is an open access article licensed under the Creative Commons

Attribution-NonCommercial-NoDerivs License (http://creativecommons.org/licenses/by-nc-nd/3.0/).

\section{Equality Plans and Gender Perception in University Students}

\author{
Isabel Pla-Julián \\ Applied Economics Department \\ Universidad de Valencia, Valencia, Spain \\ Corresponding Author \\ Jose-Luis Díez
}

Systems Engineering and Control Department, Universitat Politècnica de València, Valencia, Spain

Doi: 10.2478/mjss-2019-0051

\begin{abstract}
Despite the growing interest in the subject, the gender perceptions in the context of university studies have not been sufficiently studied so far. In this contribution, what is being proposed is a practical approach in the Spanish university system assessing the progress regarding the perception of equality among students receiving training on gender perspective in the framework of an Equality Plan. For this purpose, a case study was designed by assessing the progress as regards equality perceptions in the student body of the Universidad de Valencia Estudio General (UVEG). 338 students in grades filled out questionnaires on gender both before (225) and after (113) receiving a course in gender training. Results show Equality Plans with gender training significantly improves gender perception in university students. Academic institutions can play an essential role in ensuring developing Equality Plans with initiatives in education concerning gender equality.
\end{abstract}

Keywords: gender perceptions; equality plan; university education; research organization; gender training

\section{Introduction}

Despite the growing interest in the subject, the gender perceptions in the context of university studies have not been sufficiently studied so far. The determination of how students' perceptions differ is very important for the scientific culture in universities, "which determines attitudes (among future professionals) to gender roles and differentiates treatment of women and men" (Pollitzer, 2011: 101).

The absence of a clear perception of gender disparities in the different scientific disciplines explains, for example, why gender dimension is not properly integrated -into teaching nor research- throughout the university context. According to the European Commission report 'She figures 2015' latest statistics about the level of progress made towards gender equality in research \& innovation in Europe: "the propensity to integrate a gender dimension in research content measured in scientific articles in the EU-28 ranged from virtually zero in agricultural sciences, engineering and technology, and natural sciences to over $6 \%$ in the social sciences. Conversely, engineering and technology had one of the lowest proportions of publications with a gender dimension (0.1\% in 2010-2013), but the highest growth rate between 2002 and 2013 (14\%)" (EC, 2016a:6). In addition, gender perceptions and the research process are closely related to participation, "which governs how women and men are organized within and across different 
disciplines" (Pollitzer, 2011: 101). Athena phenomenon can be seen clearly at a European level (Hewlett et al, 2008) (Townley, 2010) (Dawson, 2014). where "there are marked differences by gender when it comes to the most popular subjects and educational pathways" (EC, 2015: 5).

For example, "men are more than two times more likely than women to choose engineering, manufacturing and construction, whereas women are twice as likely to pursue an education degree. For the student population, the proportion of women decreases from $35.57 \%$ at the entry to the university to $34,00 \%$ at the level of bachelors' degrees; it increases towards almost $36 \%$ at masters' level and decreases to $32.69 \%$ of women among PhD graduates" (CESAER, 2015: 8). In graduate and postgraduate studies (EC, 2012: 6): "In 2010, on average in the EU-27, $46 \%$ of all PhD graduates were women. However, in science, mathematics and computing, women constitute $40 \%$ of $\mathrm{PhD}$ graduates and in engineering, manufacturing and construction their share drops to 26\%". Two years later, in 2012, "women accounted for $28 \%$ of PhD graduates in engineering, manufacturing and construction, and only $21 \%$ of those graduating from computing as a reflection of the existing lack of women in the science and technological sectors" (EC, 2016a: 6).

Consequently, women are under-represented in in science \& technology (S\&T) occupations. For instance, "in more than half of the countries women are underrepresented relative to men, making up less than $45 \%$ of scientists and engineers. At the level of the EU-28, women scientists and engineers made up $2.8 \%$ of the total labour force in 2013, whereas men made up $4.1 \%$ " (EC, 2016a: 7). The factors that remove women from the STEM pipeline are a complex problem and "require a multifaceted solution and time to allow innovations to take effect" (Blickenstaff, 2005: 384).

In higher education, not only are important the gender disparities in participation in education, learning and skills development but also in access to leadership positions: women and men aren't equally represent at the doctoral level, as researchers, or as academic decision maker (Melo-Martín 2013; Ashcraft and Breitzman 2006). According to UNESCO (2018:6) "only 18\% of full professors are women and only $13 \%$ of higher education institutions in $27 \mathrm{EU}$ countries were headed by women". As a result, women don't earn the same amount of money as men, don't secure comparable research funds, don't hold the corresponding author role in scientific publications nor patent application as men (EC 2016a: 5). Considering "gender equality is good for scientific quality" (Pollitzer, 2011: 101) the afore mentioned data about horizontal and vertical gender segregation in universities gives the basis for institutional policy decisions based on the good practices to attract women and promote the appropriate mix of gender specific career development measures. For this purpose, Gender Equality Plans are the main strategy adopted by most universities as the primary tool for promoting gender equality.

Universidad de Valencia Estudio General (UVEG) is aware of gender equality problem ensuring equality through its action policies: the "I Equality Plan" (2010-2012) and the "II Equality Plan" (2013-17). Both plans cover all the staff (administrative, lecturers) and students.

Most universities have Gender Equality Plans with similar contents, but it is not very common to include gender training with specific courses allowing future professionals to receive training on equality. UVEG, as one of the leading universities in Spain and with more international projection, incorporated in his Equality Plan this pioneering initiative. The inclusion of teaching and learning activities within educational system's Equality Plans may improve gender norms, values and attitudes, laws and policies, and resources distribution.

The paper is organized as follows. First of all, a discussion about the need of introducing gender equality topics in university curricula by means of Equality plans is done, and it is also clarified how this task would allow the integration of gender perspective in university studies as a crucial aspect of equality education. Secondly, the UVEG practical approach for the integration of gender training in the university curriculum is detailed. In order to assess the effectiveness of this initiative, an observational study is designed in section 4. The last section analyses, from real data gathered from questionnaires, the perception of gender equality of future professionals and the effect on them of the proposed gender training.

A final conclusions section is also included to summarize the study findings, highlight the relevance of an institutional change in universities in order to introduce Equality Plans and integrate the gender perspective into university studies, and some good practices to favour the advancement of equality are also included. 


\section{Integrating Gender Equality Topics in University Curricula by Means of Gender Equality Plans}

From and international perspective, Education and Gender Equality Plans have been taken by UNESCO as an essential strategy of the 2030 Agenda for Sustainable Development, approved by the United Nations General Assembly in 2015. They are not only Sustainable Development Goals (SDGs) but also catalysts for the achievement of all other SDGs (UNESCO 2017:6). The SDG 4 "explicitly recognizes gender equality as a guiding principle linked to the realization of the right to education. It states clearly that girls and boys, women and men, must be equally empowered in and through education" (UNESCO 2018: 7).

The horizontal and vertical gender segregation in universities give the basis for institutional policy decisions based on the good practices and real data to promote gender equality and the appropriate mix of gender-specific career development measures.

For this purpose, research organizations need to ensure monitoring of the implementation of Gender Equality Plans through the appropriate internal procedures to introduce the gender perspective both in teaching and research (Boe et al., 2011). Gender Equality Plans must be established and monitored, including: gender perspective in their study programs, gender specific courses, and gender specific career development measures.

The Equality Plans including initiatives about education should allow rethinking central concepts and theories in relation to gender relations, in order to ensure:

1. Theoretical frameworks without gender bias.

2. Objective hypothesis.

3. The fight against academic invisibility of the major theorists, who instruct each of the disciplines.

The Gendered Innovations project (EC 2013) states that "thirty years of research have revealed that gender bias is socially harmful and expensive". Gender bias also leads to miss market opportunities. In engineering, for example, assuming a male default can produce errors in machine translation. In basic research, failing to use appropriate samples of male and female cells, tissues, and animals yields faulty results. In medicine, not recognizing osteoporosis as a male disease delays diagnosis and treatment in men. In city planning, not collecting data on caregiving work leads to inefficient transportation systems. It is crucially important to identify gender bias and understand how it operates in science and technology' (EC 2013: 6).

From a methodological framework, to analyze gender bias at university studies and research, some questions would be helpful:

1. Analyzing explicit or implicit unquestioned assumptions, preconceptions and practices about gender relations in the concepts and theories who instruct each of the disciplines.

2. Looking what are the implications of concepts and theories about gender norms, values and attitudes to formulating research questions: the choice of research topics, the methods used, what counts as evidence, data on gender and how it is interpreted. Gaps in the collection, compilation and reporting of gender- sensitive data also present a significant challenge to effective gender analysis. Analyzing what issues related to sex and gender are being misunderstood or misrepresented.

3. Concepts and theories need to be reformulated to take this new evidence into account: Who does what? Who owns what? Which factors - economic, political, legal, or culturalaffect gender relationships? How and where public or private resources are distributed? Do the existing concepts and indicators really explain gender differences? Do these concepts and theories open up spaces for gendered science as social knowledge?

In summary, some exposure to gender training will place special value on theoreticalmethodological consistency in research and educational design processes.

Additionally, UNESCO considers crucial to improve the indicators of gender inequality in education, advancing in the indicators of Teaching and learning practices e.g. teacher and student gender-related attitudes and interactions. For example, in this sense, there are 3 key indicators: "percentage of student and teachers who received training in gender sensitivity and percentage of countries that include gender equality topics in their curricula (related to gender discrimination, 
gender roles, violence, sexual and reproductive health" (UNESCO, $2018: 9$ ).

However, "equalizing education opportunities between males and females, notably in terms of participation and learning outcomes, is necessary but not sufficient for realizing gender equality in education. The 2016 Global Education Monitoring Report recognized this weakness and introduced an extended framework for monitoring gender equality in education" (UNESCO, 2018 :10). Indicators from at least five more domains are needed to frame the issue: gender norms, values and attitudes (many of which can be influenced through education); institutions outside the education system; laws and policies in education systems; resource distribution; and teaching and learning practices" (UNESCO, 2018:10).

\section{A Practical Approach in the Spanish University System: The UVEG Plans}

Universidad de Valencia Estudio General (UVEG) is aware of gender equality problem ensuring equality through its action policies: the "I Equality Plan" (2010-2012) and the "II Equality Plan" (2013-17; this plan is still in force because the new plan hasn't been approved.). Both plans cover all the staff (administrative, lecturers) and also the students to who classes in Gender Studies are offered.

Since the adoption of the I Equality Plan in 2010 the University of Valencia has offered an introductory course specifically on Gender Relations, which can be attended by any student who wishes to, at any time during their undergraduate studies. This is a pioneering initiative in Spanish universities. It is deemed essential that all graduates receive at least basic teaching in gender studies, to enable the implementation of policies of equality in social, professional, personal and familial spheres.

With the aim of specifically adapting the perspective of gender to the different branches of knowledge, four different courses in Gender Relations are given which are adapted to each of the degree courses. The four courses share some subjects in basic gender education and also include topics specifically appropriate to the different branches of study.

Below are the title and basic contents of each these four courses, as well as the respective branches of study that corresponds to each of them.

1. 'Gender Relations, science, technology and society' for the different Science, Engineering and Architecture degrees, and the Pharmacy degree. The basic content is divided into 4 part: (a) Key concepts of the analysis of gender in science and engineering; (b) Visibilisation of women in science and engineering; (c) Epistemological critique from the perspective of gender theories and scientific practices; (d) Gender, Globalisation and Diversity.

2. 'Gender Relations, thought, history y society' for degrees in the Arts and Humanities, and degrees in Teacher Training, Pedagogy and Social Education. The basic content is divided into 4 part: (a) Key concepts of the analysis of gender in history, philosophy and language; (b) Feminism in the history of thought; (c) Feminism in social and political history: (d) Gender, Globalisation and Diversity.

3. 'Gender Relations, health and society' for degrees in health sciences, except Pharmacy. The basic content is divided into 4 part: (a) Key concepts of the analysis of gender in medicine, psychology and health sciences; (b). Inequalities in health and discriminatory behaviour towards women; (c) Intervention, change and bio-psycho-social well-being; (d) Gender, Globalisation and Diversity.

4. In the case of degrees in Social Sciences and Law the course called 'Gender Relations, policies, citizenship and society'. The basic content is divided into 4 part: (a) Key concepts of the analysis of gender in law, economics, education and social sciences; (b) Citizenship, politics and education; (c) Society and economics; (d) Gender, Globalisation and Cultural Diversity.

Why has the University of Valencia opted to incorporate this pioneering initiative in Spanish universities?

1. The curriculum is aligned to the EU regulations of the European Commission and the Bologna Plan, in that it incorporates the criteria of equality and the perspective of gender in 
academic and professional education for the European labour market.

2. This offers the opportunity to broaden academic education and acquire transversal skills on the subject of gender which are complementary to those specifically included in the syllabus.

3. It improves academic profiles bringing knowledge and skills useful for future academic profiles and professional activity whatever degree course is attended.

4. It promotes innovation in education interactive communication, since semi-attendance is required, with a large proportion of on-line classes and the use of audiovisual resources.

5. In addition to this, attending this course encourages critical thinking enables one to deepen the analysis of inequality between men and women in public and private spaces, and broadens understanding of social complexity and contemporary society.

The intention is to fulfil the general directives of the new syllabi regarding the principle of equal opportunity for men and women in university education. (Royal Decree 1393/2007. BOE $n^{\circ} 260,30$ October 2007). The introduction of this subject is is broadly established in article 25 on Equality in secondary education in the Organic Law 3/2007 of the 22 of March for effective equality between men and women which is stipulated in chapter II on Administrative Actions. In articles 23 y 24 mentions the need for the integration of the principle of equality in educational: educational administration in the area of responsibility of their respective sectors will give special attention to the educational principle of equality between men and women in the curricula and at every stage of education.

Article 25 'Equality in Higher Education' refers to the promotion of teaching and investigation on the meaning and extent of equality with the aim of promoting the inclusion in the syllabi of the subject of equality, the creation of specific post- graduate courses and also studies and investigation on the subject.

Specifically, the impartation of this subject arises from the development university policies of equality. In the I Equality Plan the introduction of specific education on the subject of gender is covered in the section 3 Create a culture of equality (encouraging teaching on the subject of equality both for the administration and service personnel and the teaching and investigation staff) and in section 4 Investigation and teaching referring to the teaching staff and students more specifically.

As for the II Equality Plan, it justifies the need to offer specific courses in gender studies in section 3 Culture and Equality and section 8 Investigation and Teaching. In section 3 Culture and Equality the necessary resources are advocated for the creation of a culture of equality in universities via the promotion of the study of equality by all university personnel with the inclusion in the teaching programs of: 1 . Activities, content and courses aimed at promoting a culture of equality between men and women; 2 . Counselling and the prevention of sexual harassment and violence against women in the UV; 3 . Promotion of the progressive incorporation of the gender perspective and the drawing up of budgets for the UV, and deciding what resources from that budget would go towards gender policies; 4. Incorporation of the gender perspective in activities related to development cooperation which the UV promotes to facilitate the empowerment of women; 5. Prioritizations in the awarding of contracts to bidding companies which have implemented an equality plan. Everything else being equal; 6 . Implementation of activities which consolidate the operation of the equality commissions of the centers and services as direct collaborative bodies of the Equal Opportunities Unit in all measures which can be decentralized and coordinated from Unit; 7. Establishment of internal regulations which help students balance home life and the university timetable.

In section on Education the goal is to promote and consolidate the gender perspective in undergraduate and postgraduate studies by: 1. Assuring that all undergraduate students have the opportunity of attending a course on gender equality; 2. Promoting and consolidating interdisciplinary masters on gender and equal opportunities on all types of educational platforms; 3 . Promoting and consolidating PhDs in gender studies; 4. Promoting the use of non-sexist language in all educational material published or used in the UV; 5 . Promoting the elaboration of educational material with a gender perspective for degree courses; 6 . Including the subject of gender equality in the conference and program CONĖIXER which is directed at the teaching staff and pupils of 
secondary schools, and promoting the access of women to degree courses which are traditionally male and women and the access of men to degree courses which are traditionally female.

In the section on Investigation activities directed at introducing the perspective of gender in the investigation content by: 1 . Promoting investigation in the field of study of women, feminists and gender; 2. Promoting the inclusion of women as object and subject of investigation with the circulation of statistics on publications and promoting the publication of investigation with the perspective of gender with the creation of a financial aid package; 3. Creating an indication and/or evidence system which will enable the perspective of gender in investigation projects to be identified; 4.Organising on campus a day of seminars on the inclusion of equality in scientific investigation; 5. Stimulating a growing presence of women expert in international investigation projects until a balance is reached; 6 .Putting forward women's names for the Honorary Doctorates of the UV; 7. Encouraging women graduates to request pre and post-doctoral grants. 8. Creating a database in order to easily obtain information about the number of projects and investigation programs with a gender perspective or which are directly concerned with the equality between men and women; 9. The university will endeavor to have transparency, equity and confidentiality in all proceedings related to the selection and evaluation of investigating personnel with the aim of eliminating any sex discrimination. To that purpose parity will be ensured in all the bodies related to the selection of personnel, teaching staff and the formation of investigation teams and advisory committees.

\section{Research Method}

The case study presented next was designed with the aim of answering the following question: is the inclusion of education about gender equality in the university studies effective for improving perception of gender inequalities? In order to evaluate the paper-underlying hypothesis that there is correlation between following gender studies and advances in students' equality perception, a survey was conducted with the intention of: making visible the differences, and assess the positive impacts on gender awareness of the UVEG equality plans.

University students enrolled in gender perspective training (academic years 2017/2018 and 2018/2019) were asked to fill in the survey's questionnaires at the beginning (196) and at the end of the course (113). The data analysis involves 10 dimensions of equality in UVEG, comparing perception of equality from both an intergender and an intragender perspective, with or without specific teaching on the subject of gender. The survey was the first one on gender equality carried out at the targeted university of Social Sciences studies.

The full questionnaire is presented in the Annex, and it was used and validated in a previous work where differences between social science and engineering students were studied (Pla-Julian and Diez, 2018). The questions presented to the students tried to put some light on their opinion and perception about: the more important dimensions for achieving women and men equality (Section A), the perception about real equality (Section B), and the work-life balance (Section C).

Once questionnaire is filled in, a brief explanation of the Index of Human Development adjusted by the Inequality (IHD-I, an international indicator measuring the inequality; see http://hdr.undp.org/en) is introduced, some countries real figures are presented, and Section A questions asked again to test possible changes.

The analysis performed over that gathered data was focused on detecting perception differences between:

- Men and women

- Students that followed a basic gender equality course and those that didn't follow the course

The next section presents the more relevant results of the analysis of the gathered data.

\section{Analysis Results}

First of all, it is necessary to highlight that there are not statistical differences for the Anova test done considering a limiting $p$-value $=0.05$ (Cohen, 1988) in the question in Section A between men 
and women in the answers given before the training in gender equality. If only data after receiving the training is considered, differences are neither relevant.

However, very low p-value (i.e., big differences among data groups) can be detected if comparisons are done before and after receiving the training. In all cases (man, women or the total population), the answers given after training are very different to those given prior to training. A second conclusion in this case is that, independently of the initial values of the answers of the different groups, all of them reach an almost identical assessment after the training.

Regarding questions in Section B, some conclusions can be highlighted from figure 1 and figure 2 bar charts.

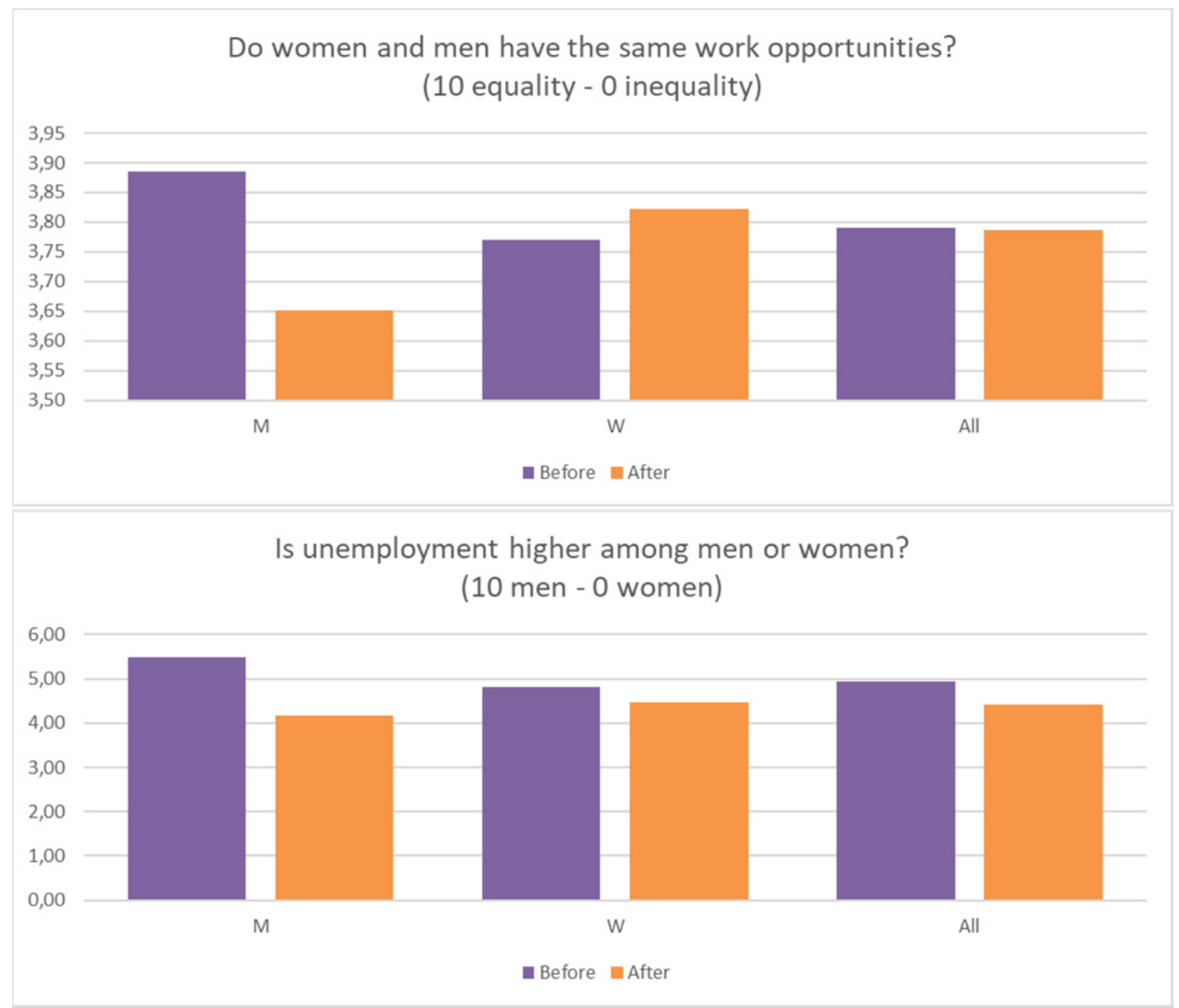

Figure 1. Perception of labour equality for the different studients' groups: women (W), men (M), and before and after the equality course. 
Who is doing more housework?

(10 women - 0 men)
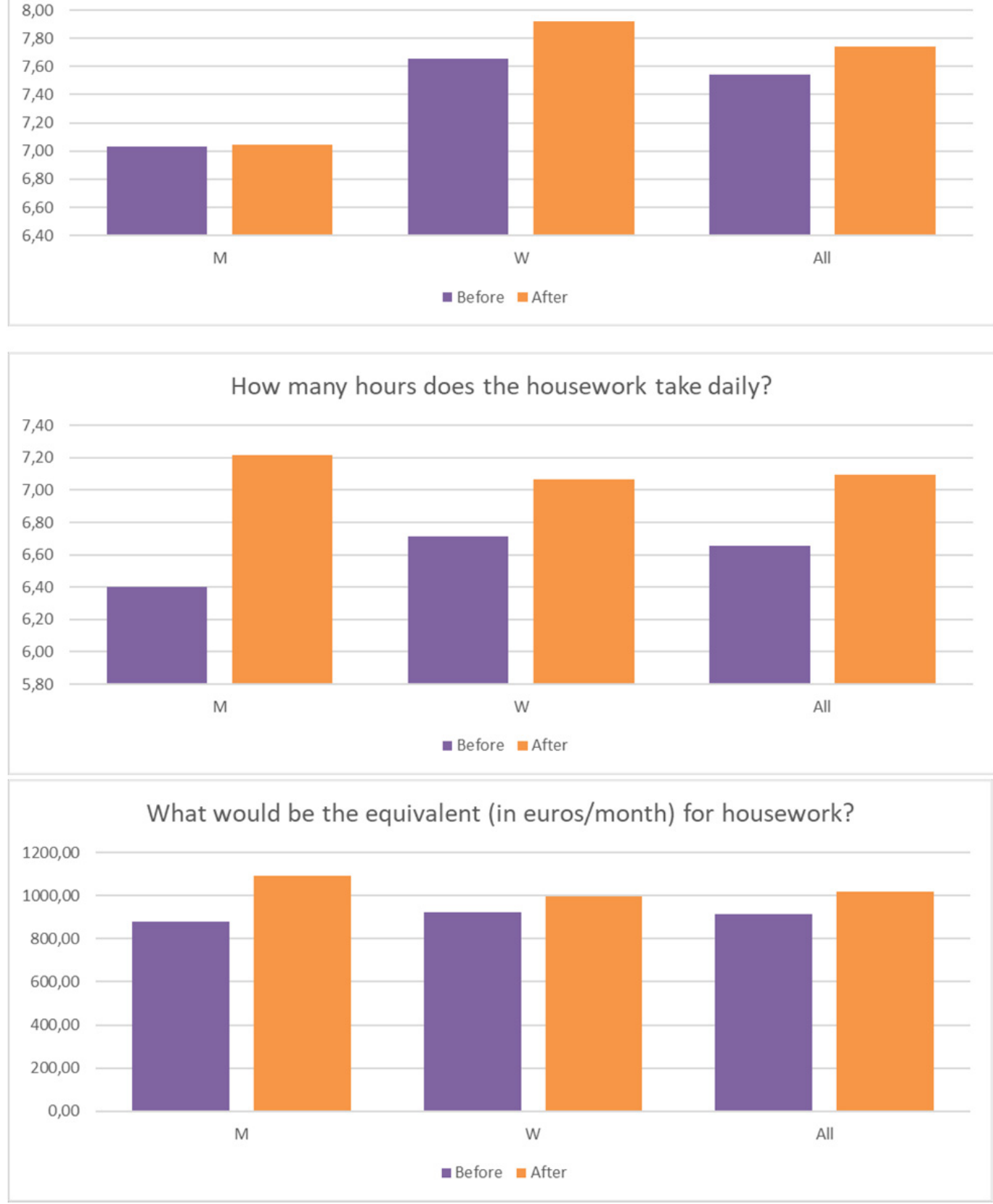

Figure 2. Perception of equality in domestic tasks for the different students" groups: women (W), men $(\mathrm{M})$, and before and after the equality course. 
Concerning attitudes to gender roles, the perception of the labour equality represented in figure 1 , there is a perception of equality (value 5) in unemployment question, and men students perceive a greater equality. The overall effect of training in this perception is very low, and perhaps it is due to the information that students already have the about this issue. In the case of opportunities of work, the overall equality valuation is lower, and the men change of perception is very important in this case.

In the perception of the equality in domestic tasks in figure 2, the training always gives place to a greater assessment of the domestic tasks (hours, wage) and a better knowledge about the real situation where the majority of these tasks are done by women.

Concerning attitudes different treatment of women and men, Figure 3 shows the perception of equality in different fields (not all the dimensions but only those with relevant differences are included in the plot). The plots are quite similar in all the groups studied, but the effect of gender training is higher in men. In general, wage and access to the degrees are perceived as the causes of greater inequality. Additionally, men are less aware of inequalities: they have a perception of equality in the access to studies and health.

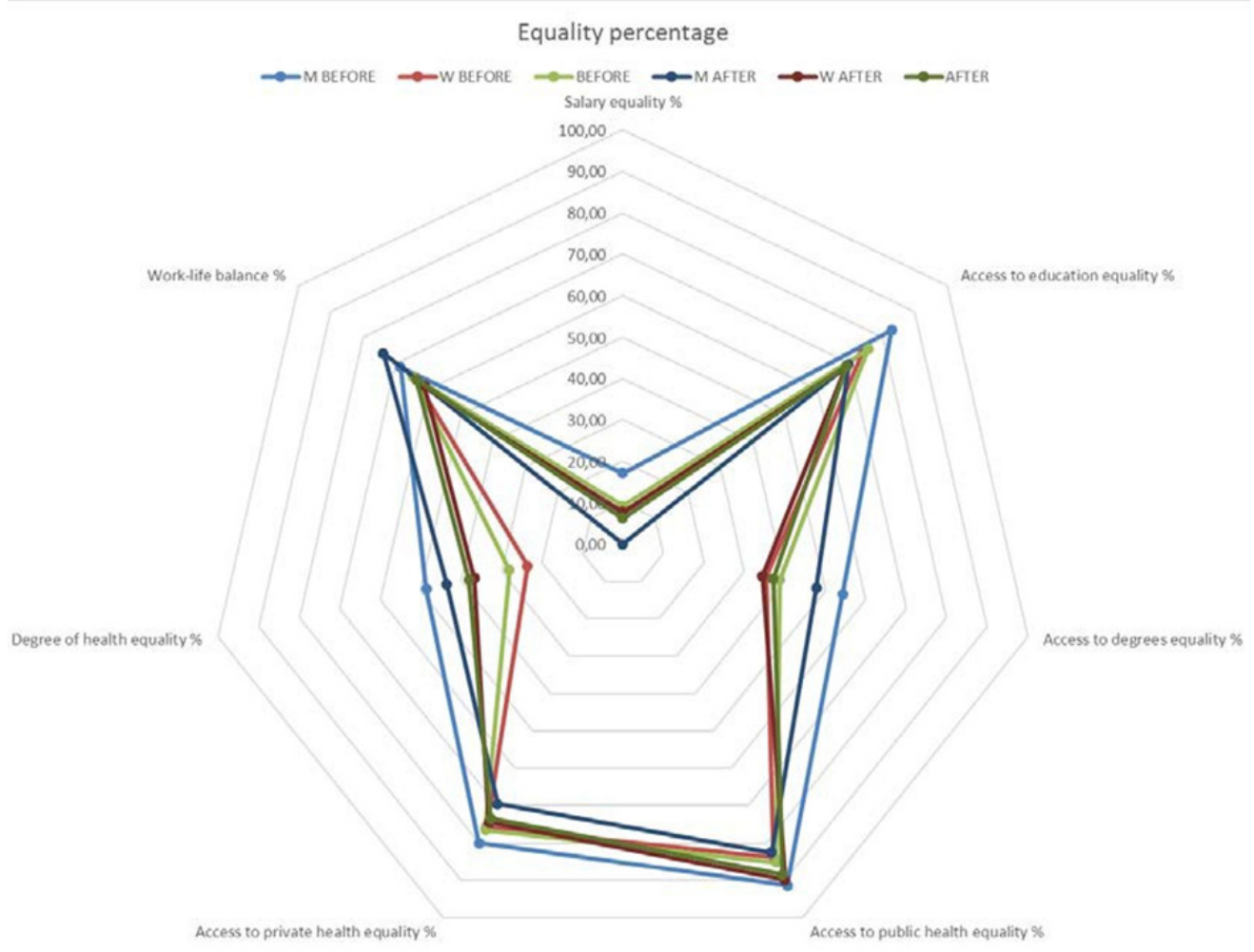

Figure 3. Perception of equality in different fields for the different students" groups: women (W), men (M), and before and after the equality course. 


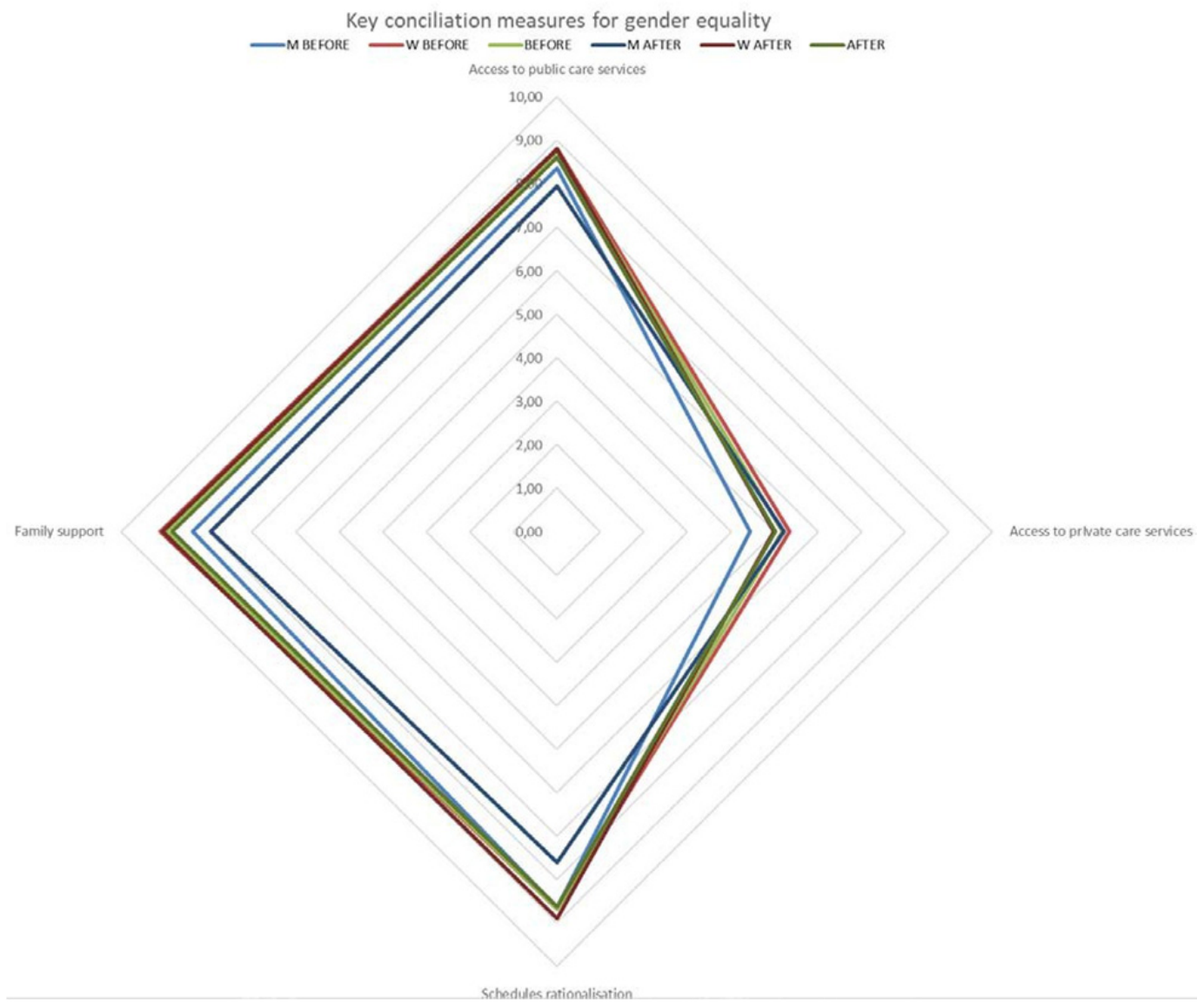

Figure 4. Key conciliation measures for gender equality in different for the different students' groups: women (W), men (M), and before and after the equality course. 


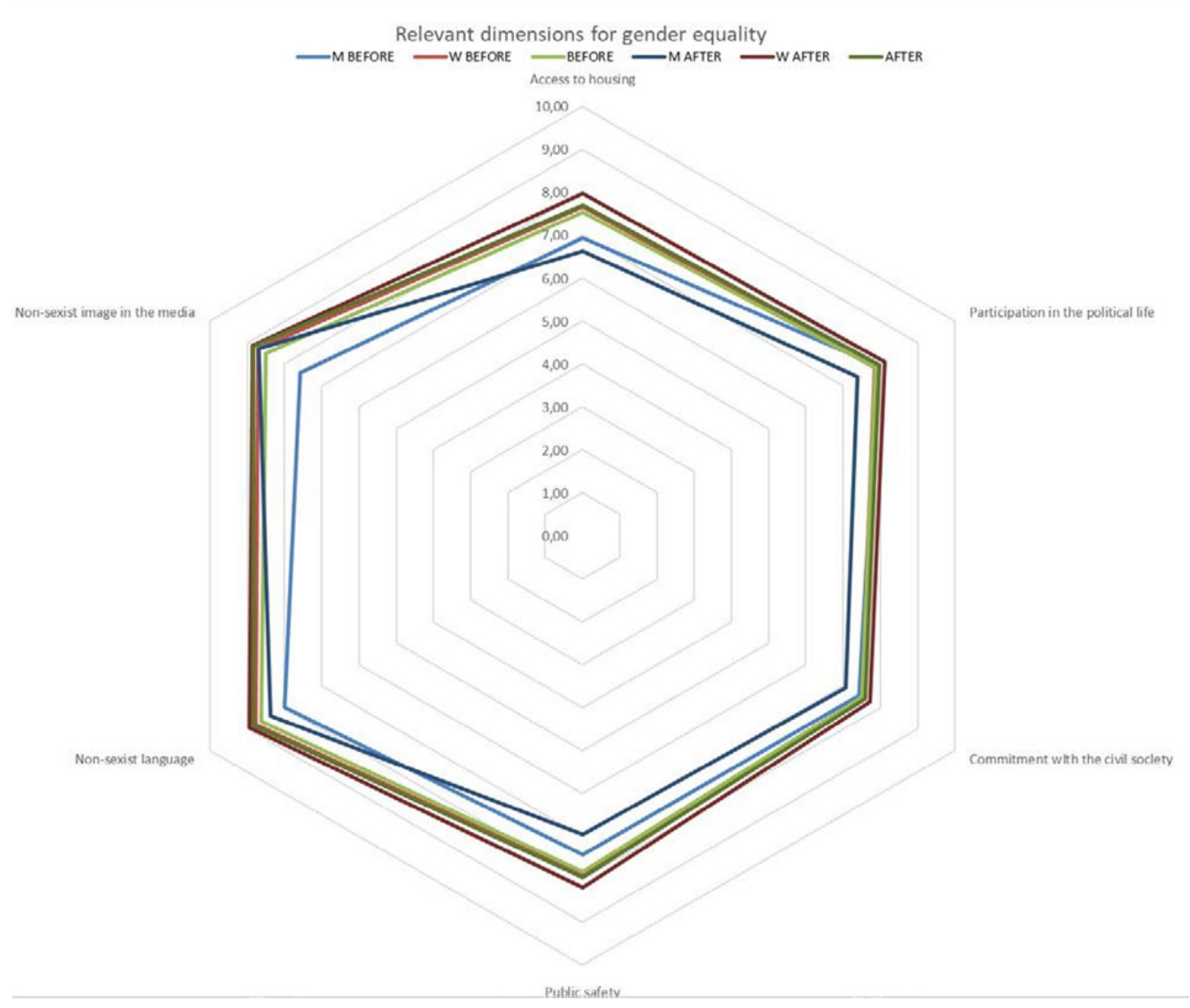

Figure 5. Relevant dimensions for gender equality in different for the different students" groups: women (W), men (M), and before and after the equality course.

Regarding the analysis measures for conciliation all of them are revealed as are very important except the access to private services. In figure 4 can be observed the answers for: access to public care services, schedules rationalization, family support. In all cases, men perceived conciliation measures less important, and the overall effect of training is not significative in this case.

The importance given to the dimensions to reach the gender equality is shown in figure 5 . The same pattern is detected here: all of them are revealed as are important and, in all cases, men perceived dimensions less important. And the overall effect of training is not significative in this case.

The influence of indicator IHD-I knowledge in the students is very similar for all groups, and being more sensitive to this new information those students that have gone through the training. Figure 6 shows the students opinion about different dimensions' importance in this case. In this case, men students are those that consider some items less important, and the effect in men before training is the biggest.

Summarizing, the data analysis gives us the following results: men are less aware of inequalities, and a positive evolution has been observed in students after following a course in gender training provided by the equality plan of the UVEG. This is especially important in the case of men. 


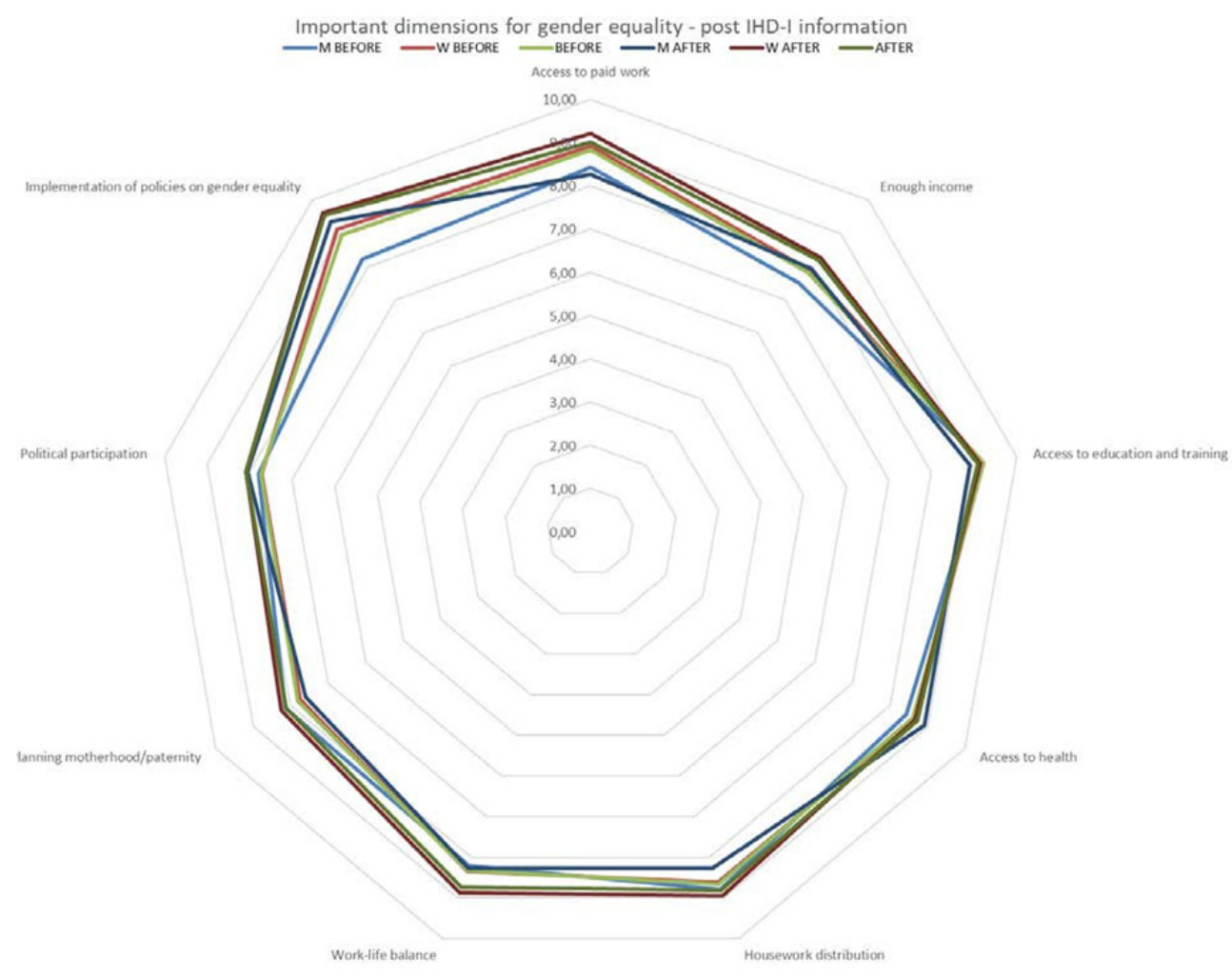

Figure 6. Important dimensions for gender equality after the information about IHD-I index in different for the different students" groups: women (W), men (M), and before and after the equality course.

\section{Conclusions and Recommendations}

The results obtained in this study demonstrate a different gender equality perception between men and woman. Additionally, a positive evolution has been observed in students after following specific gender studies provided by the equality plan of the UVEG. There is a lot to be done for university students, and to develop curricula that are gender-sensitive can be the easiest solution (UNESCO 2018). Therefore, it is evidenced that it would be very important to introduce gender studies within Gender Equality Plans, especially in the case of men.

The outcomes prove already interesting and relevant for benchmarking, and as basis for policy decisions. It can be easily done by using the proposed questionnaire (or a modified version more adequate for the institution under study) for regular monitoring of different aspects of the gender dimension, and assessment of specific gender measures.

Finally, as a recommendation, it is important to highlight the relevance of an institutional change in universities in order to introduce Equality Plans and integrate the gender perspective into university studies that would favor the advancement of equality.

Research performing organizations have a unique role to play in equality plans to improve structural changes. Equal job quality, career advancement and top-level representation can be achieved by advancing towards a gender-equal working environment. However, the European Research Area (ERA) Survey points that only 'around $36 \%$ of research performing organizations (RPOs) indicated that they had introduced Gender Equality Plans in 2013' (EC 2016b). 
Several efforts have been put in place at international level aimed at producing structural changes in university institutions, and must be taken into account as good practices to follow beyond Gender Equality Plans.

The European Commission convened an Expert Group on Structural Change in February 2011. As a result of their deliberations they produced a report entitled 'Structural Change in the scientific institutions: excellence, equality and efficiency in research and innovation' (EC, 2012).

Parallel to this initiative, the European Summit on Gender (EGS) (EC, 2016b) - which is being held since 2011 (EC, 2011) - was organized by GenSET (GENSET, 2011) with the objective of supporting progress towards excellence and efficacy in research while promoting innovation at all levels by integrating the gender perspective. Available information and conclusions of the latest EGS (EPWS, 2018:1) should be revised by all those involved in the Gender Equality Plans development, and integrated in their institutions.

Additionally, it is worth to mention the resources provided by the SAGA UNESCO STEM, with a gender advancement initiative "to reduce the gender gap in STEM fields in all countries at all levels of education and research, developing new and better indicators to provide tools for evidence-based policy-making, build capacity in Member States for data collection on gender in STEM, as well as prepare methodological documents to support the collection of statistics" (UNESCO, 2016: 4).

Both education and Gender Equality Plans are an integral part of the 2030 Agenda for Sustainable Development, as a tool to achieve SDG 4 on gender equality in education. Additionally, the 2016 Global Education Monitoring Report recommends an integral framework for monitoring gender equality with indicators from key concerns as gender perceptions, training practices and educational policy (UNESCO, 2018).

As a closing remark to all readers, their importance to existing and future research is vital the inclusion of gender trainings in any organizations to advance in the perception and sensitization in inter-gender and intra-gender equality. This matters for human rights, for inclusion, for sustainable development, but also from a pragmatic point of view related to advantages and better quality of life.

\section{References}

Ashcraft, C, Breitzman, A (2006) Who Invents IT? An Analysis of Women's Participation in Information Technology Patenting. Accessed 2 December http://www.ncwit.org/sites/default/files/legacy/pdf/PatentReport_wAppendix.pdf

Blickenstaff, JC. (2005) Women and science careers: leaky pipeline or gender filter? Gender and Education 17 (4): 369-386.

Boe, MV, Henriksen, EK, Lyons, T, Schreiner, C. (2011). Participation in science and technology: young people's achievement-related choices in late-modern societies. Studies in Science Education, Vol. 47, No. 1, 37-72.

Cohen, J. (1988). Statistical power analysis for the behavior sciences (2nd ed.). NY: Routledge.

CESAER (2015) Cesaer task force human resources. Gender equality and European Universities of sciences and technology. Accessed 21 July 2018 https://www.cesaer.org/content/statements-andpublications/2015/cesaer-gender-equality-oct15-incl-annexes.pdf

Dawson, E (2014). Equity in informal science education: developing an access and equity framework for science museums and science centers. Studies in Science Education, Vol. 50, No. 2, 209-247.

EC (European Commission) (2011), European Gender Summit 2011. Accessed 21 July 2013. http://www.gender-summit.eu/index.php/about-the-summit/pastevents

EC (European Commission) (2012), Structural change in research institutions: Enhancing excellence, gender equality and efficiency in research and innovation. Accessed 2 May 2013, http://ec.europa.eu/research/science-society/

EC (European Commission) (2013), Gendered Innovations. How Gender analysis contribute to research. Accessed 252014.2 June 25 ://ec.europa.eu/research/sciencesociety/document_library/pdf_06/gendered_innovations.pdf

EC (European Commission) (2016a), She figures 2015. Accessed 28 May 2016. https://ec.europa.eu/research/swafs/pdf/pub_gender_equality/she_figures_2015-final.pdf

EC (European Commission) (2016b), European Gender Summit 2016. Accessed 12 May 2016, http://www.gender-summit.eu/gs9-about.

EPWS (European Platform of Women Scientifics) (2018), 15th Gender Summit -London: United in Science and Through Science. Accessed 10 May 2018, https://epws.org/15-gender-summit/

GENSET (2011), Manifesto for Integrated Action on the Gender Dimension in Research and Innovation. Accessed 2 June 2013, http://www.gender-summit.eu/ 
Hewlett, SA, Luce, CB, Servon, LJ, Sherbin, L, Shiller, P, Sosnovich, E \& Sumberg, K (2008), The Athena Factor: Reversing the Brain Drain in Science, Engineering, and Technology, Boston: Harvard Business.

Melo-Martin, I. (2013). Patenting and the Gender Gap: Should Women Be Encouraged to Patent More? Science and Engineering Ethics 19 (2): 491-504. DOI: 10.1007/s11948-011-9344-5

Pla-Julián, I. \& Díez, J.L. (2018) Gender Equality Perceptions of Future Engineers, Engineering Studies, DOI: 10.1080/19378629.2018.1530242

Pollitzer, E (2011). Why Gender Should be a priority for our attention in Science. Interdisciplinary Science Reviews 36(2), DOI: 10.1179/030801811X13013181961266

Townley, C (2010). More on Enrolling Female Students in Science and Engineering. Science and Engineering Ethics 16 (2): 295-301. DOI: 10.1007/s11948-009-9160-3

UNDP (2015), Informe sobre Desarrollo Humano 2015. El ascenso del Sur: Progreso humano en un mundo diverso, Accesed 2 April 2016, http://hdr.undp.org/sites/default/files/2015_human_development report_overview_-_es.pdf.

UNESCO (United Nations Educational, Scientific and Cultural Organization) (2003), UNESCO's Gender Mainstreaming Implementation Framework for 2002-2007. 7EGM/ST/2010/REPORT. Accessed 5 May 2016, http://unesdoc.unesco.org/images/0013/001318/131854e.pdf

UNESCO (United Nations Educational, Scientific and Cultural Organization) (2016), SAGA (STEM and Gender Advancement) Improved measurement of gender equality in science equality in science, technology, engineering and mathematics. Accessed 4 July 2016. http://unesdoc.unesco.org/images 10024/002450/245006E.pdf

UNESCO (2018): Global Education Monitoring Report. Gender review. Sustainable Development Goals United Nations Educational, Scientific and Cultural Organization Meeting our commitments to gender e quality in education. Accessed 4 September 2018. http://www.ungei.org/resources/files/GEM_Report_Gender _Review_2018(1).pdf

\section{Annex. Questionnaire}

I. Gender Equality Dimensions

a. Which of the following dimensions you think are the most important to attain the equality among women and men in Spain? (Please, reorder in importance order): Access to paid work, Enough income, Access to education and training, Access to health, Housework distribution, Work-life balance, Planning motherhood/paternity, Political participation, Implementation of policies on gender equality.

b. Once ordered, please give them a grade from 0 (less important) to 10 (most important).

c. Do you think that there exist any other dimensions that are also important to achieve the equality among men and women? Please, enumerate and grade them.

II. Real Equality Perception

a. Dou you think women and men have the same access to work opportunities? Please, grade from 0 to 10.

b. Dou you think that there are more unemployed men that women? In which proportion from $0 \%$ to $100 \%$ ?

c. Who do you think do more housework, men or women? In which proportion from $0 \%$ to $100 \%$ ?

d. How long (in hours) do you think daily housework takes? What would be a fair salary for it?

e. Dou you think that men and women are equally paid for the same work?

f. Dou you think that men and women have the same access to education?

g. Dou you think that men and women have the same access to all university degrees?

h. Which schools are better for equality, those with segregated education or with co-education?

i. Dou you think that men and women have the same access to public health?

j. Dou you think that men and women have the same access to private health?

k. Dou you think that men and women have the same degree of health?

III. Work-Life Balance

a. Dou you think men and women attain work-life balance? In the same degree? If not, more men than women or more women than men?

b. Which of these dimensions do you think are more important for work-life balance? Access to public care services, Access to private care services, Schedules rationalisation, Family support.

c. Which of these dimensions would you chose for gender equality? Access to housing, Participation in the political life, Commitment with the civil society, Public safety, Non-sexist language, Nonsexist image in the media. 